\title{
Analysis of Social Networking Websites and Its Effect on Academic Students
}

\author{
Jahangeer Qadiree ${ }^{1}$, Dr. Pratiama Gautam ${ }^{2}$ \\ ${ }^{1}$ Research Scholar, Aisect University, Institute of Science and Technology, \\ Chikload Road, District Raisen 462001, MP \\ ${ }^{2}$ Dean of Information Technology Department, Aisect University, Institute of Science and Technology, \\ Chikload Road, District Raisen 462001, MP
}

\begin{abstract}
Social Networking Websites have enlarged widely worldwide and are used by different types of communities for different purposes. The effect of social networking websites can be good on students but if we look closer on social networking websites. Today; Social Networking Websites leads an important role in running the future and carrier of students. At present there are billions of profile identities of the world wide on Social Networking Websites. The social networking websites are continuously disturbing students from their studies. As the students main focus for using such social networking websites should be centered focused but unfortunately the student are using social networking websites for complete destroy of their carrier. As the Social Networking Websites were the only link between many users across the world, but the social networking websites become just a fertile exercise among the students, teenagers and even adults. This research paper presents the social networking websites effect on student's carrier, and the life of teenagers. It also shows that how the social networking websites are today effective for students pursuing academics, youth and teenagers.
\end{abstract}

Keywords: Social Networking, Education, Students, Effect of Social Networking Websites

\section{Introduction}

Internet the very common and essential part of our daily life. The very large numbers of tasks that can be done using the internet technology like communication, Research, Education and so it is very important. As we can say that with the progress in the internet technology we are progressing in every domain of life as it not only makes our tasks troublefree but it saves a lot of time. Now a day it is used for various purposes depending upon the requirement. Its countless users who use it for education purposes but the other side there are also a very large number of communities including majority of teenager and adults who use Internet only for social networking. Internet is very vibrant evolution of technology but when we discuss about the social networking it is totally dangerous for youth who are misusing it for casual desires [2]. The concept of social networking is quite simple to understand, it is totally a web based system that provides the facility to its users to build identity on it and connect them to other friends and communicate with them at a central location $[1,2]$. The social networking websites are owned and controlled by many international companies because the social networking websites are commonly visited at a time by millions of people thus the companies in reverse can get the benefit of advertisements and get paid; users are totally free from cost to register himself in social networking websites [1]. After registration People get connected to one another and then post news, information, videos and pictures etc. [3, 4]. Although social networking websites can be used for good purposes but it is countless users generally use it only for involvement of digital snapshots, highlight demographic material and information, securities exposing, and online conversations, this is because various of its users motivate the user for such kind of unprofessional actions [4] and these users has almost spoiled the image of social networks.

\section{History of Social Networking Websites}

The social networking technology has emerged in 1990 with web 2.0 namely classmates.com in the year 1995 focusing the connection between former classmates, and in the year 1997 a new social networking website arise sixdegrees.com which permit its users to build a profile identity on it and share information among friends. Later nn the year 2002 the first modern friendster.com social networking website was launched and was popular among different groups. In May 2003 a new face of social networking websites come into existence named linkedin.com emerge with various amazing features, but in the year 2004 a new social networking website facebook.com was launched that had changed the total image in the social networking history of social media and web services. It also changes the definition of social networks. In year 2005 social networking websites become very much popular and advance with the features of real time updates, and permit to its users with various exciting features and tools to modify the whole front end look of the website on his profile which is a step towards advancement.

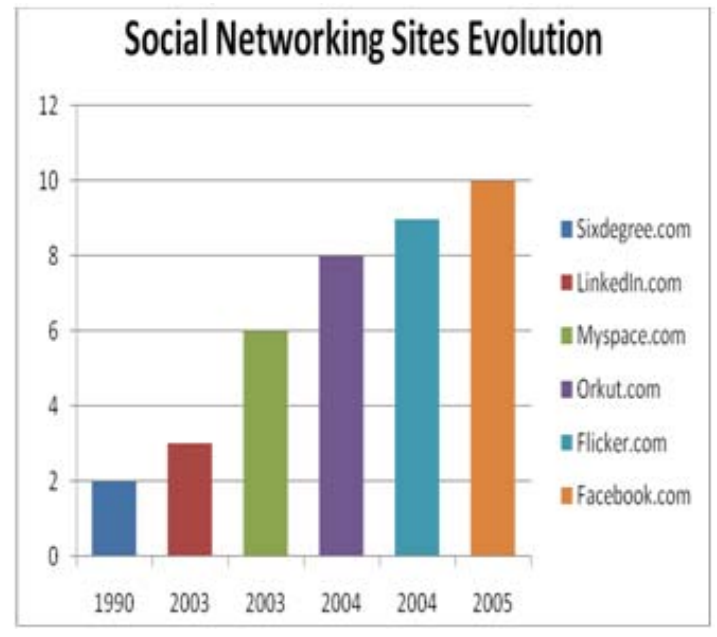




\section{International Journal of Science and Research (IJSR) \\ ISSN (Online): 2319-7064}

Index Copernicus Value (2013): 6.14 $\mid$ Impact Factor (2014): 5.611

\section{Research Approach}

When we look about the social networking law and sovereignty unfortunately we don't have any such law or authority for Social networks, it is an international cyber law that the user must be minimum 18 years old or more to register in any social network website. We don't have any such kind of authority that will check the user who is going to register on social networking website is it acceptable age or not. The research emphasis the Qualitative research method for analysis to collect the behavioral changes understanding in depth that are caused by social networking websites.

After the survey it has been analyzed that there are a large number of underage users, who are using social networking websites and has reported that there are various communities who have one Identity or profile to facilitate on social networking website, but according to survey its has been also reported there are also various communities who facilitate their identity by fake profiles as shown in figure 1.2.

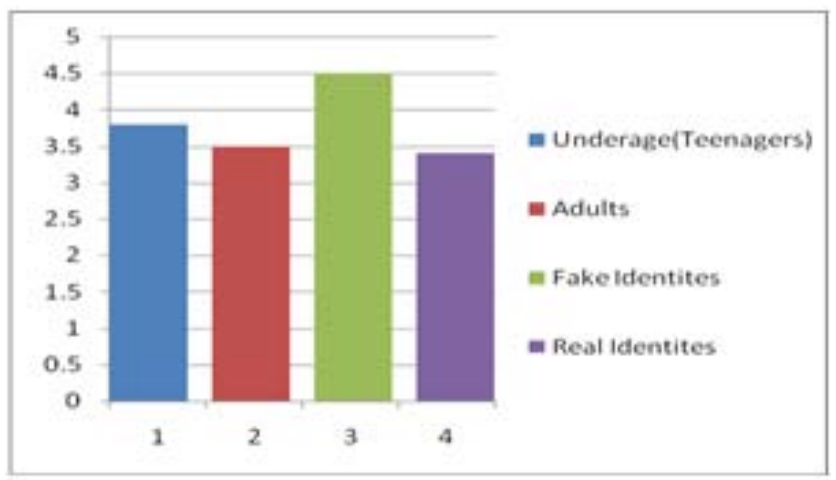

Figure 1.2 shows the usage of fake profiles and underage users. According to the analysis survey, there exists a very large number of fake profiles in social networking websites, and thus is reverse these fake profiles perform various unprofessional violations on social Networking websites as they register themselves as a fake profile with someone else and upload of inappropriate material like Porn videos and nude images which is very much common act of violation ${ }^{[7]}$.

\section{Research Method}

The research begins with the analysis survey. The survey was performed among the randomly selected most popular social networking website users with 16 to 24 years age group students. The students 16 to 24 of age were chosen because they are the early and advanced users of information technology applications especially social networking websites.

The research survey was done using 2.0 web service, and the data have been collected through direct interview. The research survey data were also been collected through website survey's, emails, questioning them to understand the effects, their behavioral changes that are caused by the social networking websites on their academic life.

\section{Analysis of Data and Interpretation}

Table 1: Usage purpose of Internet

\begin{tabular}{|c|c|}
\hline Uses & Percentage \% \\
\hline E-Mail & $30 \%$ \\
\hline Surfing & $25.8 \%$ \\
\hline Social Networking & $38.7 \%$ \\
\hline Others & $5.5 \%$ \\
\hline Total & $100 \%$ \\
\hline
\end{tabular}

Table 1 shows the usage percentage of internet with $30 \%$ for emailing and $25 \%$ for surfing. These are the two main common uses of internet. The social networking websites used by the academic students were reported $38.7 \%$ and that is why the social networking websites are growing very fast. The other internet usage was reported as low percentage.

Table 2: Memberships in social networking websites

\begin{tabular}{|c|c|}
\hline Member of SNS & Percentage\% \\
\hline Yes & $98.0 \%$ \\
\hline No & $2.0 \%$ \\
\hline Total & $\mathbf{1 0 0 \%}$ \\
\hline
\end{tabular}

In the table 2 it was recorded that $98 \%$ of sample was members of social networking websites. Divided the data down further, $55 \%$ of the respondents were the members of today's most popular percentage of users social networking website facebook.com [4] and 33\% of respondents were the twitter.com members, and rest of the members was recorded to other social networking websites mentioned were Myspace, LinkedIn, Friendester, and google+.

Table 3: Usage of social networking websites

\begin{tabular}{|c|c|}
\hline Hours & Percentage\% \\
\hline Less than 1 Hour & $75.1 \%$ \\
\hline 1-2 Hour & $21.2 \%$ \\
\hline 3-5 Hour & $3.7 \%$ \\
\hline Total & $\mathbf{1 0 0} \%$ \\
\hline
\end{tabular}

In the above table, it has been shown that $75.1 \%$ of social networking websites users use it less than one hour and there were no respondents who use social networking websites for more than 6 hours. Majority of the data were exposed to social networking websites for short duration due to various personal issues like, no internet access at their home or no interest in social networking websites.

According to another survey it has been analyzed the ratios of teenage users by categorizing the social networking website users in three different categories one is teenagers $(12-16)$ second one is young adults $(17-22)$ and the third one is adults $(23+)$ as shown in figure 1.3. 


\section{International Journal of Science and Research (IJSR) \\ ISSN (Online): 2319-7064}

Index Copernicus Value (2013): 6.14 | Impact Factor (2014): 5.611

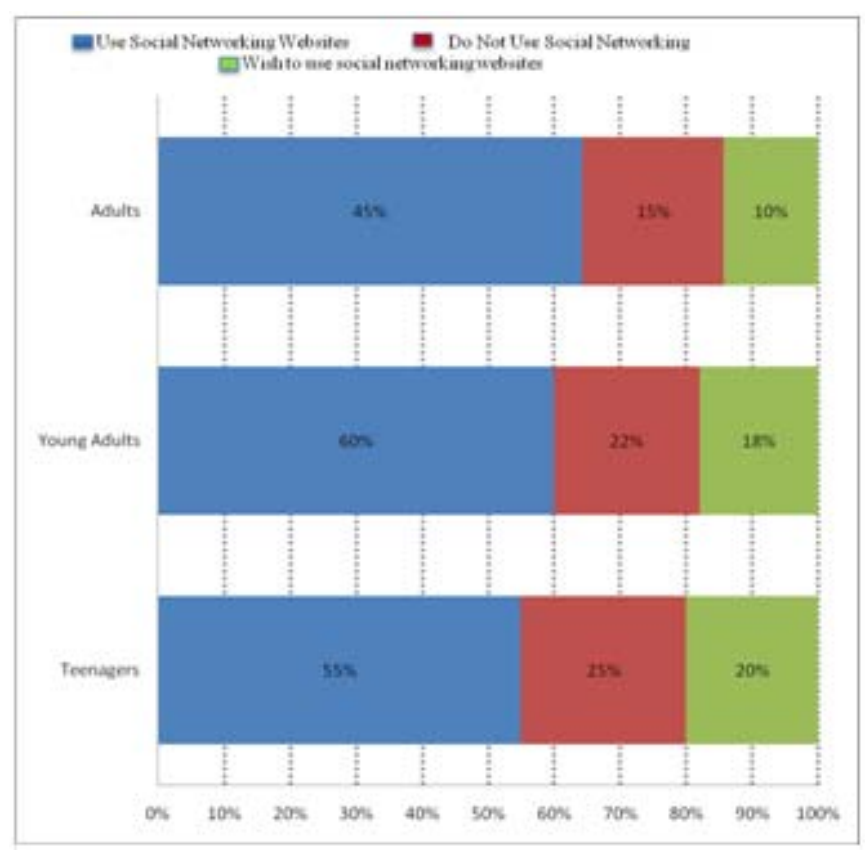

As the figure 1.3 shows the ratios of teenage users with average of using social networking websites, not using social networking websites and in wish to use social networking websites. The average of users are social networking addict users which use social networking websites regularly on daily basis, while those users who wish to use social networking websites are those who don't have such kind of devices or permission or any other problem to use social networking websites but they wish to use social networking websites. It has been also been analyzed that there also exists another community of users who don't use any social networking websites, because they dislike social networking or any other personal cause.

\section{Social Networking Websites and Its Effect on Students Education}

Education is the essential part of every individual's life. Education is more important for every teenager than anything [4]. The Teenager shows more interest for using the social networking websites, but unfortunately Social Networking websites affect their education very badly [3]. In previous research it has been examined that more than $95 \%$ of college level students use social networking websites. The fast growing Technology has also shown a fast development by producing various ease of use communication devices include personal computers, ThinkPad's, Tablets, Smartphone's and even a simple mobile phone etc,. These academic students are using such small communication devices to ingress social networking websites at whatever time any place. The academic students use it for e-learning. There is no doubt that the Technology is a step towards goodness, but if we look the technology in another way, it can be very dangerous for social networking devotee. Providing facility of social networks of addiction to any teenager and even an adult, as the academic expectations is not sufficient for that student who suffers from social isolation [6].
Social Networking websites diverts the total concentration of the students and grab them towards non educational, unethical and unsuitable actions such as useless chatting, time wasting by useless information searching and not doing their jobs. As the social networking websites are introducing many attractive features like gamming, advertisements etc. so that the social networking website users can never get enough of these attractive features. The Students cannot get succeed because they have no sense of their coming future and competitions in their profession.

Social networking websites provide new applications day by day and snatch the interest of students and grow the number of users. Users are totally free of cost to use these applications, so that's why the users use the applications without any installation and any other regulations any time anywhere. These free of cost applications betray students from their target, and they do not concentrate on their education. As all of the social networking websites applications are based on 2D screen so by looking long time same screen could cause high blood pressure and nervousness which could be harmful for their academic life as well as health. According to survey students do not take their food on time and are not sleeping on time which causes a very non serious approach with education. Social networking websites connect them with one another so they not even care to solve their home jobs and they get in touch with their elders and seniors to assist them in their educational material. Social networking websites provide unacknowledged life to the students, those students who even not speak in front of anyone could feel freedom in their life. When they use social networking websites they feel like in heaven but this weakness kills their inner self qualities forever. Becoming addict of social networking websites feels like they have many good friends but in real all of the contacts are false contacts and thus effects by going far from your family, close ones, and other associations that could be very much harmful for their personal life and academic career. It changes the mindset of students towards education life completely. This virtual life of student changes his thoughts from education towards other unprofessional activities and by living inside fantasy world student slowly starts to avoid the academic life and studies. A very unprofessional action performed by almost every user on social networks is intrude. It is concept of understanding is the other users by spying their profiles, actions, likes, comments performed [8] In this regard opposite genders can be charm by one another and to find quality of any friend almost each and every academic student destroy months and weeks on eavesdropping. According [1] The U.S. Military banned use of social networking websites on soldiers and Canadian Government has also debar employees from social networking websites while the U.S. Congress has proposed to block all such social networking websites in schools and library. Social networking websites plays a very negative impression on people of irrespective of age. The teenagers are badly victimized. International and national jurisdiction must take action against such social networking websites. 


\section{International Journal of Science and Research (IJSR)}

ISSN (Online): 2319-7064

Index Copernicus Value (2013): 6.14 | Impact Factor (2014): 5.611

\section{Conclusions}

The growing social networking websites has shown an important change in teenagers for their academic life as well as their behavior. The social networking websites are need of the hour, but not at the cost of ethics and education of the students. It could ruin the future of academic teenagers as well as adults and it had a very bad effect on education as it is discussed above. There is no third party or any other community that will detect the actions that are being performed by the users, so it is strong recommendation of parents that they should look their children's activities on social networking websites and don't let them use social networking websites freely. It is also a strong advocacy for Government and international cyber Jurisdiction to take a strong part and prohibit these types of websites. It is also recommended to every parent that they should strictly debar their children from using these social networking websites

\section{References}

[1] Danah M. Boyd \& Nicole B. Ellison, "Social Network websites: Definition, History, and Scholarship", In Journal Of Computer-Mediated Communication, Vol. 13, Issue 1, October 2007.

[2] S. Kuppuswamy, P. B. Shankar Narayan, "The Impact of Social Networking Websites on the Education of Youth", In International Journal of Virtual Communities and Social Networking, Vol. 2, Issue 1, page 67-79, January-March 2010.

[3] J. Cain, "Online Social Networking Issues Within Academia and Pharmacy Education" In American Journal of Pharmaceutical Education, vol. 72, Article 10, February 2008 . http://www.ncbi.nlm.nih.gov/pmc/articles/PMC2254235 /

[4] N. Ellison, C. Steinfeld, C. Lampe, "Spatially bounded online social networks and social capital: The role of Facebook" In Proceedings from the annual conference of the international communication association. Dresden, Germany, June 2006.

[5] Jeff Cain, "Pharmacy Students' Facebook Activity and Opinions Regarding Accountability and EProfessionalism" In American Journal of Pharmaceutical Education, Vol. 73, Issue 6, October 1, 2009. http://www.ncbi.nlm.nih.gov/pmc/articles/PMC2769526 /

[6] Dr. Anamika Bhargava \& Minaxi Raina, "The Influence of social media on Indian teenagers", In International Journal of Science, Technology \& Management, Vol. 04, Issue 01, page 246-252, 2015.

[7] M. Asfandyar Khan1, "The Impact of Social Media and Social Networks on Education and Students of Pakistan", In Journal of Marketing, Vol. 73, Issue 5, page 90-102, September 2009.
Author

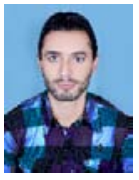

Jahangeer Qadiree is presently pursuing his Doctor's Degree (PHD) in Information Technology at Aisect University, Institute of Science and Technology. He has received his Bachelors Degree in 2011 from Computer Application with $75 \%$ and Masters Degree in the discipline of Information Technology with $84.5 \%$ in the year 2014 from Aisect University. His research area is Networking, Software Engineering. Cloud Computing, Data Mining. 